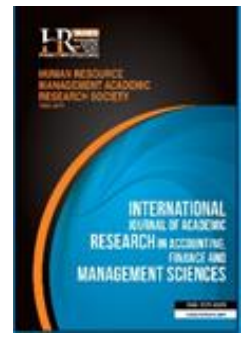

International Journal of Academic Research in Accounting, Finance and Management Sciences

Vol. 8, No.2, April 2018, pp. 95-101

E-ISSN: 2225-8329, P-ISSN: 2308-0337

(c) 2018 HRMARS

www.hrmars.com

To cite this article: Anghelache, C., Anghel, M.G., Dumitrescu, D., Avram, D. (2018). Romania's Strategy in the Field of Research and Innovation, in the Context of the European Union, International Journal of Academic Research in Accounting, Finance and Management Sciences 8 (2): 95-101.

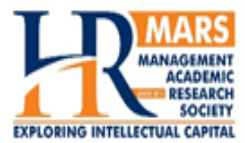

http://dx.doi.org/10.6007/IJARAFMS/v8-i2/4186 (DOI: 10.6007/IJARAFMS/v8-i2/4186)

\title{
Romania's Strategy in the Field of Research and Innovation, in the Context of the European Union
}

\author{
Constantin ANGHELACHE ${ }^{1}$, Mădălina-Gabriela ANGHEL ${ }^{2}$, \\ Daniel DUMITRESCU ${ }^{3}$, Doina AVRAM ${ }^{4}$ \\ ${ }^{1}$ Bucharest University of Economic Studies/„,Artifex” University of Bucharest, Romania, ${ }^{1}$ E-mail: actincon@yahoo.com \\ ${ }_{2}^{2}$,Artifex" University of Bucharest, Romania, ${ }^{2}$ E-mail: madalinagabriela anghel@yahoo.com \\ ${ }^{3}$ European Center for Services Investments and Financing, Romania, ${ }^{3} E$-mail: danidumitrescu@yahoo.com \\ ${ }^{4}$ Bucharest University of Economic Studies, Romania, ${ }^{4}$ E-mail: doina.avram@gmail.com
}

\begin{abstract}
The evolution of each country must also be based on cooperation in economic sciences. To the extent that each Member State progresses and participates in the launch of joint projects, it is also possible to strengthen the European Union (EU). This article will undertake a study that highlights the role of international cooperation. The authors present details of Romania's $R \& D$ and innovation strategy by 2020, in line with the strategy adopted by the European Union in its "Horizon 2020" program in this area. Examples of projects are given. In this article, the authors focus on presenting Romania's strategy and policy in the field of industrial, technological and innovation research, in the general context of the European Union's "Horizon 2020" development program. Elements of Romania's development-innovation strategy are highlighted by 2020 and beyond. We present details of some projects initiated by our country in the context of the European Union.
\end{abstract}

Key words Research-innovation, project, development, technology, strategy, European Union

Received: 12 May 2018 (C) The Authors 2018

Revised: 25 May 2018 Published by Human Resource Management Academic Research Society (www.hrmars.com)

Accepted: 31 May 2018 This article is published under the Creative Commons Attribution (CC BY 4.0) license. Anyone may reproduce, distribute, translate and create derivative works of this article (for both commercial and noncommercial purposes), subject to full attribution to the original publication and authors. The full terms of this license may be seen at: http://creativecommons.org/licences/by/4.0/legalcode

\section{Introduction}

In this article, the authors start from the fact that the realization of economic and scientific cooperation projects contributes to the economic strengthening and development of each state but also provides positive effects for the European Union. The directives adopted by the European Union clearly show the concern to achieve better results, which will ensure the economic evolution of each country but also of the European Union as a whole, initiated by Romania in industrial research, technology and innovation. There is reference to Romania's financing capacity, with the need to provide annually at least $1 \%$ of GDP for research and innovation. It is also emphasized that by intensifying the research and innovation activity, Romania will ensure a more consistent economic growth and the possibility to participate in important projects of the European Union. Projects taking place within the European Union are open to all member countries but participate in those countries that have experience in certain areas without which the respective projects could not be completed. This article analyzes a series of concrete data and refers to some major research projects included in Romania's development, innovation strategy by 2020 and beyond. In the context of the above, it is clear that the assessment that the Member States of the European Union would develop in several stages is incorrect. Most steps are in fact major projects or 
insignificant projects, and the participation of states in one of the two categories can be done in close coordination with the high degree of specialization a state or another has in a field subject to cooperation in the projects technical-scientific, research-innovation, economic, in general terms.

\section{Literature review}

Anghel et al. (2016) addressed a series of issues regarding the importance of banks in the absorption of community funds. Anghelache et al. (2016) presented an IT \& C platform that can be used in community funded projects. Barbosa and Faria (2011) studied the role of institutional variation in European countries in explaining the differences between the intensity of innovation at the industry level. Bravo-Ortega and Marín (2011) examined the relationship between R \& D activity and productivity using several indicators. Cincera and Veugelers (2013) studied the EU gap in research and development intensity. Gomez-Puig (2008) drew attention to the implications of monetary integration. Srholec (2009) investigated whether foreign ownership promotes innovation cooperation with non-affiliated partners at home, abroad, or both. Chalmers (2013) discussed the influence of interest groups in the European Union. Hernández-Cánovas and Martínez-Solano (2010) studied the correlation between credits and the financing of small and mediumsized enterprises in the European continental banking system. Lima and Cardenete (2007) investigated the implications of European funds for a regional economy. Pedersini (2014) conducted a study on the existence and strength of Europe's industrial relations cluster groups and analyzed their long-term trends. Santos Silva and Tenreyro (2010) discussed the empirical assessment of the costs and benefits of monetary unions. Schenone (2010) tried to identify whether banks are exploiting the advantage of information. Schneider and Häge (2007) analyzed the degree of government involvement in infrastructure provision, based on a study of 20 OECD countries. Stępniak (2015) focused on the application of interactive maps in an investment process carried out in local government units. Tosun (2014) conducted a comparative study on the absorption of regional funds.

\section{Research methodology and data. Results and discussions}

The field of research and innovation (C \& I) occupies a leading role in the Europe 2020 strategy, being a determinant for achieving smart, sustainable growth and meeting societal challenges. In addition to direct and immediate impact (product, process and service innovation and environmental, scientific publications, patents), C \& I also has a broader economic impact by gaining larger market shares, achieving more productivity increased industrial competitiveness and more efficient use of resources.

According to the analysis carried out in 2007-13, some EU countries, such as Denmark and Germany, have funded the public research system even after the economic crisis, maintaining a high level of public spending on research and development, and other countries in Central and Eastern Europe (Estonia and the Czech Republic) show strong growth in R \& D intensity as a result of the use of European Structural Funds since 2007. On the other hand, countries that have allocated resources well below the EU27 average for RDI and before 2007 have further reduced these allocations beyond 2007. In this situation are Romania, Bulgaria, Croatia and Hungary. The poor financing of RDI in these countries leads to delays in the development of knowledge-based economy in these countries.

In Romania, research and development policy in the field of technology and innovation has materialized in the approval of a Romanian RDI strategy for 2014-2020, highlighting the importance this field can have for increasing economic competitiveness in the context of European policies in the field. Romania has also taken into account the drafting of this document to the priorities of the European Union presented in the framework of the Europe 2020 strategy, the Europe - Innovation Union initiative and the most important research and development program of the European Union - Horizon 2020.

Europe 2020 priorities mean an increase that has the following characteristics: smart, sustainable and inclusive, and one of the most relevant objectives of the European RDI Strategy is that by $2020,3 \%$ of EU GDP will be allocated to investment RDI.

The National Strategy for Development and Innovation Research - SNCDI, was built on a study of the national RDI market, funded by a contract with JASPERS. This study then evolved by highlighting the economic sectors with potential in the field. This strategy can be implemented through a series of subordinate instruments that include operational programs in force from 2014 to 2020. Thus, the RDI field 
will be achieved through ROP, POCU, NRDP, but especially through the Operational Program Competitiveness.

This strategy adopts the pragmatic nature of industrial research, moving away from purely speculative research, so as to follow the international trends of RDI orientation towards achieving practical and economic impact. SNCDI is also based on an innovation partnership based on the following four pillars: Budgetary resources (state-assured by allocating a percentage of GDP), Predictability (clear standards and rules for RDI activity), Public-Private Partnerships (so as to attract at least 1\% of GDP in 2020), Researchers (reaching a number of researchers similar to the EU average).

Romania's RDI strategy has identified those areas of the economy that have potential for growth and can make a significant contribution to increasing economic competitiveness. Thus, Romania's intelligent specialization priorities were identified as areas of economic competence with high competence and where our country would have real or potential competitive advantages over other national economies, which would implicitly lead to economic growth and the increase of Gross Domestic Product. Thus, SNCDI has identified the following economic areas as having an important economic and employment boosting role: tourism and ecotourism, textiles and leather, wood and furniture, and creative industries. Automotive, ICT and food and beverage processing have been identified as presenting competitive economic dynamics and Health and pharmaceuticals, energy and environmental management and bio-economy have added value and important features of innovation and technological development.

Also, SNCDI also proposes a set of priorities of public relevance aiming at attracting resources and creative ideas in areas of RDI that bring solutions to existing societal needs. In this case, the public sector is the one that supports the identification and attraction from private or public actors of innovative, disruptive solutions.

Even if there is a growing focus on RDI trading, fundamental research is also important in the next period, and it is important to stimulate RDI supply assessed on the scientific quality of proposals calculated in line with international standards. A prestigious example of this is the large Extreme Light Infrastructure Nuclear Physics (ELI-NP) infrastructure project. In fact, the 2014-2020 financial frameworks will mark the launching of two major pan-European research infrastructures: the Magurele project at ELI-NP and the Tulcea project called the International Center for Advanced Research Fluvii - Delte - Marii Danubius.

The following interventions are also financed: large CD infrastructures (including 2 major projects: ELI -NP and Danubius); developing networks of CD centers coordinated at national level and linked to European and international networking and providing researchers with access to scientific publications and European and international databases; creating synergies with RDI actions of the EU's ORIZONT 2020 Framework Program and other international RDI programs; attracting staff with advanced skills from abroad to strengthen RDI capacity.

ELI-NP was selected by the most important scientific committee in the field of Nuclear Physics in Europe - NUPECC - in the Long Term Plan of Nuclear Physics in Europe as a major infrastructure. The ELI-NP infrastructure will consist of two components: a high-intensity laser system with two $10 \mathrm{PW}$ laser arms capable of reaching $10^{23} \mathrm{~W} / \mathrm{cm}^{2}$ and electric fields of $10^{15} \mathrm{~V} / \mathrm{m}$; a very intense, brilliant $\left(10^{13} \mathrm{~V} / \mathrm{s}\right)$ beam with a bandwidth of $\sim 0.1 \%$, with $E_{\gamma}$ up to $19,5 \mathrm{MeV}$, which is obtained by the incompatible Compton retrospection of photons from a laser beam onto a very bright, intense beam, of electrons $\left(E_{e}\right.$ up to 720 $\mathrm{MeV}$ ) produced by a classic accelerator.

This infrastructure will create a new European laboratory with a wide range of fields of science from fundamental physics, innovative nuclear physics and astrophysics to applications for nuclear materials, radioactive materials management, materials science, and the life sciences. ELI-NP will be the most advanced research infrastructure in the world that focuses on the study of photonuclear physics and its applications, consisting of a high-intensity laser consisting of two lasers with ultra-short pulses of 10PW and the brightest beam adjustable gamma rays. Launched in November 2007, the preparatory phase of ELI involved nearly 40 research and academic institutions covering 13 EU Member States: Institute of Plasma Physics and Laser Microfusion, Warsaw, Poland; Research Cluster "Matter and Radiation Science" Technische Universität Darmstadt, Germany; Institute of Experimental Physics, Faculty of Physics, University of Warsaw, Polond; Institute for Nuclear Research of the Hungarian Academy of Sciences (MTAAtomki); Institute of Nuclear Physics, University of Cologne, Germany; INFN LNS Catania, Italy; Friedrich 
Schiller University, Jena, Germany; "II. Physikalisches Institut" of Justus-Liebig University, Gießen, Germany; Institut de Physique Nucléaire, Orsay, France; Henryk Niewodniczanski Institute of Nuclear Physics, Polish Academy of Science, Polond; The University of Strathclyde, Glasgow, UK; GSI Helmholtzzentrum für Schwerionenforschung GmbH, Darmstadt, Germany; TÜV SÜD Nuclear Technologies, UK; The Science and Technology Facilities Council, UK; Queen's University of Belfast, UK; University of Ruse "Angel Kanchev", Bulgaria; Helmholtz-Zentrum Dresden-Rossendorf, Germany; Technische Universitat Munchen, Germany; Elettra-Sincrotrone Trieste, Italy; IZEST École Polytechnique, France; Department of Physics, University of York, UK; Centro de Laseres Pulsados Ultracortos Ultraintensos, Spain; Joint Research Centre of the European Commission; Centre National de la Recherche Scientifique/Commissariat a l'Energies Alternatives/L'Ecole Polytehnique/L'Institute d'Optique Graduate School/L'Universite de Paris Sud, France; State Research Institute Centre for Physical Sciences and Technology, Lithuania; Centre National de la Recherche Scientifique (LULI - Laboratoire d'Utilisation des Lasers Intenses), France; University of Birmingham, UK; National Centre for Nuclear Research, Poland.

This phase of 36 months aimed at bringing the project to the legal, organizational, financial and scientific level. Within this activity, the scientific community involved in the preparatory phase identified four branches of research and applications in its field: Laser Science Attosecond: temporal investigation of dynamic electrons in atoms, molecules, plasma and solids at the ignition scale (10-18 secs per second); High beam energy science: Developing and using dedicated beam lines with ultra-short pulses of high energy radiation and particles that nearly reach the speed of light; Laser induced photonuclear physics: nuclear physics methods for studying target laser interactions, new nuclear spectroscopy, new photonuclear physics, and so on.; Ultra High Field Science: Investigating laser interaction in an energy field where relativistic laws could stop to be valid.

In his mission, ELI will conduct a powerful technology transfer for European SMEs and large firms. The ELI agenda will include the training of scientists and engineers who aspire to many disciplines associated with Extreme Light. Located in Magurele, only $12 \mathrm{~km}$ from the center of Bucharest, ELI-NP users benefit from all metropolitan infrastructure and services. The concentration of eight research infrastructures of national interest at Magurele brings the highest scientific visibility in Romania, with five national research and development institutes (Nuclear, Laser, Plasma and Space Sciences, Physics of Materials, Optoelectronics, Seismology), Physics and two engineering (optoelectronics and design of nuclear installations). ELI-NP is supervised by the National Institute of Horia Hulubei for Physics and Nuclear Engineering (IFIN-HH), dedicated to research and development in the field of Nuclear Physics and Nuclear Engineering as well as related fields including astrophysics and particle physics, field theory, mathematics and computational Physics, atomic physics, life and environmental physics.

DANUBIUS-RI will be a pan-European research infrastructure dedicated to interdisciplinary studies of large-river systems. It will allow and support research into addressing conflicts between society requirements, environmental change and environmental protection in river and maritime systems around the world. DANUBIUS-RI is developed by partners from eleven European countries, expressing interest from the scientific community in many other countries in Europe and around the world. Its goal is to become operational by 2022. DANUBIUS-RI has been included in the ESFRI 2016 Roadmap (European Strategic Forum on Research Infrastructures) and is an emblematic project of the SUERD (EU Strategy for the Danube Region).

The DANUBIUS-RI project is headed by Romania. Financing commitments have so far been granted by four countries (Germany, Italy, Romania and Spain) with a political commitment from seven (Bulgaria, Greece, Hungary, Ireland, Moldova, the Netherlands and the United Kingdom). Expressions of interest and support from the scientific community have been received from these countries and from 16 other European and non-European (Austria, Czech Republic, Finland, France, Lithuania, Norway, Poland, Serbia, Switzerland, Turkey, Ukraine, Azerbaijan, China , India, Morocco and the USA. Expressions of interest and support from prestigious organizations have been expressed: Austria: WasserCluster Lunz; Azerbaijan: National Academy of Sciences, Geology and Geophysics Institute; Bulgaria: Bulgarian Academy of Sciences: National Institute of Meteorology and Hydrology; National Institute for Geophysics, Geography and Geodesy; Institute of Oceanology; Space Research and Technology Institute; Institute of Biodiversity and Ecosystem Research; and Geological Institute; China: Huazhong University for Science and Technology; 
Cehia: Academy of Science, Institute of Landscape Ecology; Silesian University in Opava; Finland: University of Eastern Finland, Faculty of Forestry Environment; France: Perpignan University (CEFREM); Research Centre Lille Nord Europe (INRIA); National Centre for Scientific Research (CNRS): Institute for Ecology and Environment (INEE); and Institute for Universe Science (INSU); Germany: Terrestrial Environmental Observatories (TERENO); Federal Institute of Hydrology (BfG); Institute of Coastal Research, Zentrum Geestacht Centre for Materials and Coastal Research (HZG); Greece: Hellenic Centre for Marine Research (HCMR); Hungary: Hungarian Academy of Sciences: Centre for Ecological Research; and Institute for Geological and Geochemical Research (IGGR); Eotvos Lorand University of Budapest, Institute of Geography and Earth Sciences; Szechenyi Istvan University of Gyor; India: EIRC Consulting Pvt. Ltd; Ireland: MaREI Centre, Environmental Research Institute, University College Cork; Italy: National Research Council of Italy (CNR): Institute of Marine Science (ISMAR); and Institute for Coastal Marine Environment (IAMC); National Institute of Experimental Oceanography and Geophysics (OGS); Consortium for Coordination of Research Activities Concerning the Venice Lagoon System (CORILA); National Institute of Geophysics and Vulcanology (INGV); Lithuania: Klaipeda University, Infrastructure and Development Affairs; Moldova: Academy of Sciences of Moldova: Institute of Geology and Seismology; and Institute of Chemistry; Morocco: University Hassan II, Casablanca, Faculty of Science and Techniques Mohamedia; Netherlands: Deltares; UNESCO-IHE Institute of Water Education; Norway: Norwegian University of Science and Technology, Faculty of Natural Sciences and Technology; Norwegian Institute for Water Research (NIVA); Norwegian University of Life Science, Faculty of Veterinary Medicine and Biosciences; Poland: Wroclaw Medical University, Department of Pharmaceutical Biology; Romania: Ministry of Education and Scientific Research; Romanian Academy; Consortium of scientific and industrial community led by the National Institute for Marine Geology and GeoEcology (GeoEcoMar) and the National Institute for Biological Sciences (INSB);mSerbia: University of Novi Sad; University of Belgrade; Spain: Politehnic University of Catalunya: SARTI Research Group, OBSEA; Underwater Observatory; Civil Engineering of Barcelona; and Departament d'Ingineria Hidraulica; Instiuto del Ciencias del Mardel Consejo Superior de Investigaciones Cientificas, Centre for Advance Studies of Blanes; Switzerland: Federal Institute of Aquatic Science and Technology (Eawag); Turkey: Gazi University, Faculty of Pharmacy; Ukraine: Ukrainian Hydrometeorological Centre Black and Azov Seas; Ukrainian Centre of Ecology of the Sea (UkrSCES) Odessa; National Mechnicov University of Odessa; Odessa State Environmental University; State Agency of Fisheries of Ukraine, Odessa Centre of Southern Research Institute of Marine Fisheries and Oceanography; National Academy of Science of Ukraine, State Institution "Hydroacustic Branch of Geophysics S I Subbotin"; United Kingdom: University of Stirling, School of Natural Sciences; University of Birmingham, School of Geography, Earth \& Environmental Sciences; Science and Technology Facilities Council, Astronomy Technology Centre; University of Hull, Department of Geography, Environment and Earth Sciences; Plymouth Marine Laboratory; University of Cambridge, Department of Geography; Scottish Universities Environmental Research Centre (SUERC); Natural Environment Research Council, Centre for Ecology and Hydrology (CEH); USA: Water Institute of the Gulf.

Surface water is a fundamental global resource that sustains a number of important ecosystems and diverse habitats; they have a key function in global biogeochemical cycles and are essential for food and energy production. Rivers, deltas and coastal areas have been facing increasing pressures in recent years. There have been drastic changes in land use, overexploitation of natural resources and hydraulic upgrading through dam, dig and recanalization. The resulting degradation has serious implications for human communities and environmental health. Biodiversity access points to the earth and water interface provide essential ecosystem services and are characterized by extremely dynamic processes. However, the demands of the global human population exert a significant and increasing pressure on the functionality of these systems. Challenges due to the complexity and complex dynamics of large sea and river systems have led to a general lack of planning for integrated and adaptive management.

The ability to cope with the challenges caused by these pressures was limited by disciplinary boundaries and lack of interdisciplinary initiatives to undertake, develop and implement the fundamental and integrated research required. This is exemplified by the current status of research (and research infrastructure) dedicated to river systems and their transitional aquatic environments, which face multiple pressures from the dynamic interaction of physical, chemical and biological processes with "natural" and anthropogenic drivers. This is evident in very well-managed basins where, across Europe (and globally), 
many large urban centers have developed along the coast, on or near estuaries at the freshwater-marine interface. In general, there is a growing concern that coastal deltas and estuaries are at "critical points". The concern is that our knowledge of the functioning of the system is insufficient to inform the levels of resistance and sensitivity to "collapse" in river-sea systems.

A fundamental new approach to research is needed to promote the objective of better environmental management of river systems, especially at the interface between freshwater and marine waters. This requires world-leading science, including research that is of immediate importance and immediate social influence in facilitating interdisciplinary research into freshwater and marine science. The required research must fall within the traditional disciplinary and geographic boundaries and be implemented in a consistent and qualitative framework to gain a more rigorous understanding of: (i) the dynamics of the environmental system that can be compared across Europe; (ii) the implications of marine collection/pressures on the function of the system; (iii) the consequences of the human agency; and (iv) the importance of preserving or strengthening the ecosystem services that these systems provide to society to ensure their future well-being.

\section{Conclusions}

The study concludes that this international economic and scientific cooperation, by reducing it to cooperation in this area within the European Union, has always played an important role in strengthening the European Union. Romania has a precise strategy in the field of innovation research, whereby planned and completed projects are of interest to our country as well as to the European Union as a whole. Romania participates, in cooperation with other EU Member States, or more widely in Europe, to projects such as "Danubius", which is of interest to the entire continent. Economic and scientific cooperation within the European Union is a factor in enhancing the capacity to initiate major projects and to link individual Member States' efforts to ensure a harmony and correlation of individual efforts that materialize in major projects to ensure industry growth, services and other areas in the interest of each participating state, but in this way also the European Union as a whole. Another conclusion is that within the European Union, the projects being initiated are open to all Member States, but participation is only made to the extent that each Member State makes a concrete, technical and scientific contribution (the result of research and innovation), financial or skilled workforce. So there is a need for improved cooperation on projects within the European Union so as to highlight the growth of the economy of the Member States and of the Union as a whole.

\section{References}

1. Anghel, M.G., Dumitrescu, D., Dumitrescu, D. and Niţă, G. (2016). Role of banks in European funds absorption to maintain macroeconomic stability. Romanian Statistical Review, Supplement, 9, 43-49.

2. Anghelache, C., Soare, D.V. and Dumitrescu, D. (2016). IT\&C Platform Used in Projects Financed from European Union Funds, Romanian Statistical Review, Supplement, 6, 59-67.

3. Barbosa, N. and Faria, A.P. (2011). Innovation across Europe: How important are institutional differences?. Research Policy, 40 (9), 1157-1169.

4. Bravo-Ortega, C. and Marín, A.G. (2011). R\&D and Productivity: A Two Way Avenue?. World Development, 39 (7), 1090-1107.

5. Cincera, M. and Veugelers, R. (2013). Young leading innovators and the EU's R\&D intensity gap. Economics of Innovation and New Technology, 22 (2), 177-198.

6. Gomez-Puig, M. (2008). Monetary integration and the cost of borrowing. Journal of International Money and Finance, 27, 455-479.

7. Srholec, M. (2009). Does foreign ownership facilitate cooperation on innovation? Firm-level evidence from the enlarged European Union. The European Journal of Development Research, 21 (1), 4762.

8. Chalmers, A.W. (2013). Interests, Influence and Information: Comparing the Influence of Interest Groups in the European Union. Journal of European Integration, 33 (4), 471-486. 
9. Hernández-Cánovas, G. and Martínez-Solano, P. (2010). Relationship lending and SME financing in the continental European bank-based system. Small Business Economics, 34 (4), 465-482.

10.Lima, C. and Cardenete, A. (2007). The effects of European funds on a regional economy: an applied general equilibrium analysis, Applied Economics Letters, 14 (11), 851-855.

11.Pedersini, R. (2014). European industrial relations between old and new trends. Stato e mercato, 3, december, 341-368.

12.Santos Silva, J. and Tenreyro, S. (2010). Currency Unions in Prospect and Retrospect. Annual Review of Economics, 2, 51-74.

13.Schenone, C. (2010). Lending Relationships and Information Rents: Do Banks Exploit their Information Advantage?. Review of Financial Studies, 23(3), pp. 1149-1199.

14.Schneider, V. and Häge, F. (2007). Europeanization and the retreat of the state. Journal of European Public Policy, 15 (1), 1-19.

15.Stępniak, C. (2015). Interactive maps as a tool of investment processes support. Collegium of Economic Analysis Annals, 38, 247-258.

16.Tosun, J. (2014). Absorption of Regional Funds: A Comparative Analysis. Journal of Common Market Studies, 52 (2), 371-387. 